\title{
Um panorama das propriedades físicas e químicas de substratos utilizados em horticultura no sul do Brasil ${ }^{(1)}$
}

\author{
GILMAR SCHAFER (2)*, PAULO VITOR DUTRA DE SOUZA(2), CLAUDIMAR SIDNEI FIOR ${ }^{(2)}$
}

\begin{abstract}
RESUMO
O uso de substratos para cultivos em ambiente protegido culminou com a necessidade da utilização de materiais com características químicas e físicas específicas; estas últimas assumindo um papel fundamental no cultivo de plantas hortícolas. O objetivo deste estudo foi apresentar resultados de análises físicas e químicas dos substratos encaminhados ao Laboratório de Substratos para Plantas da UFRGS nos últimos três anos, visando estabelecer um panorama do setor de substratos, comparando-os com valores referenciais citados na literatura. Neste período foram realizadas 307 análises físicas e 479 análises químicas, que serviram de base para este estudo. As análises físicas realizadas foram densidade em base seca e curva de retenção de água (porosidade total, espaço de aeração, água disponível e água remanescente). As análises químicas foram condutividade elétrica (CE) e potencial hidrogeniônico $(\mathrm{pH})$. Os principais resultados, referentes às características físicas, demonstraram que os substratos apresentaram faixa ampla de densidade em base seca podendo ser utilizados para diversos tamanhos de recipientes, porém a maioria apresentouse fora da faixa ideal para as demais características físicas. Os substratos em cultivo no sul do Brasil são, em sua maioria, alcalinos e com condutividade elétrica bem diversa, com considerável número de amostras acima do recomendado.
\end{abstract}

Palavras-chave: horticultura, ambiente protegido, cultivo em recipientes, produção de mudas, meios de cultivo.

\begin{abstract}
An overview of the physical and chemical properties of substrates used in horticulture at southern Brazil

The cultivation in greenhouse and containers culminated with the necessity to use substrates with formulations as well as distinguished chemical and physical characteristics, the last ones assuming a key role in cultivation of horticultural plants. The aim of this study is to present results of physical and chemical analyses of substrates forwarded to an commercial laboratory (Laboratório de Substratos para Plantas - UFRGS) for the last three years, aiming to establishing a panorama of the substrates area and comparing them with reference values cited in the literature. In this period were performed 307 physical and 479 chemical analyses, which were the basis for this study. Physical analyses performed were the density in dry basis and the water retention curve (total porosity, air space, available water and remaining water). Chemical analyses were the electrical conductivity (EC) and the $\mathrm{pH}$. The main results concerning physical characteristics, demonstrate that the substrates present wide range of density in dry basis and may be used for different sized containers; however most substrates analyzed is out of ideal range for the other physical characteristics of the substrate. For the chemical characteristic the substrates in cultivation in southern Brazil are mostly alkaline and the electrical conductivity of the substrates in cultivation is very diverse, with considerable number of samples above the recommended.
\end{abstract}

Keywords: horticulture, greenhouse cultivation, container production, seedling production, culture media.

\section{INTRODUÇÃO}

O avanço do cultivo em ambiente protegido e em recipientes culminou com a necessidade de utilização de substratos com formulações e características distintas. Dentre estas, as características físicas e químicas dos materiais assumem importante papel. Como características físicas citam-se a densidade em base úmida e seca; a porosidade total; o espaço de aeração e a retenção de água a baixas tensões de umidade. As características químicas mais importantes nos substratos compreendem o valor do $\mathrm{pH}$, condutividade elétrica e/ou teor total de sais solúveis e os teores de nutrientes disponíveis (KÄMPF, 2005).

A porosidade total, que tem como valor ótimo $85 \%$, é condicionada por macro e microporos, que representam o espaço de aeração, água disponível (composta pela água facilmente disponível e tamponante) e remanescente do substrato (DE BOODT e VERDONCK, 1972; CATTIVELLO, 1991). Os autores afirmam que o espaço ocupado por macroporos é que condiciona o espaço de aeração do substrato, espaço este correspondente à água liberada entre as tensões de 0 e $10 \mathrm{hPa}$ da curva de retenção, sendo o seu valor de referência, de 20 a $30 \%$ do volume do substrato. Para o percentual de água facilmente disponível, que é à água liberada entre as tensões de 10 e 50 $\mathrm{hPa}$, considera-se como ideal entre 20 a $30 \%$; e, para a água tamponante, que representa a água retida entre as tensões de 50 e $100 \mathrm{hPa}$, o ideal está por volta dos $5 \%$. Embora a água remanescente não seja disponível à maioria das plantas, sua principal importância está na influência sobre algumas propriedades do substrato, como: condutividade elétrica, capacidade térmica e condutividade hidráulica

\footnotetext{
(1) Recebido em 08/12/2014 e aceito em 14/10/2015

(2) Universidade Federal do Rio Grande do Sul (UFRGS), Porto Alegre-RS, Brasil. * Autor correspondente: schafer@ufrgs.br
} 
(SCHMITZ, 2002), sendo os valores considerados como ideais de 20 a $30 \%$.

A densidade expressa a relação entre a massa e o volume do substrato e, em geral, a densidade seca é utilizada como principal parâmetro de avaliação, pois a densidade úmida varia muito conforme o teor de água do material no momento da análise. Normalmente, os valores de referência de densidade seca para substratos são de 350 a $500 \mathrm{~kg} \mathrm{~m}^{-3}$ (CONOVER, 1967) ou de 400 a $500 \mathrm{~kg} \mathrm{~m}^{-3}$ (BUNT, 1973). Kämpf (2005) salienta que a densidade deve levar em consideração a altura e volume do recipiente de cultivo.

Para o valor de pH em água, Kämpf (2005) descreve nove faixas, desde extremamente baixo $(<4,5)$, até extremamente alto $(>6,9)$, sendo considerado como valor ótimo para substratos sem solo mineral, a faixa de 5,2 a 5,5. Especificamente para floricultura, Cavins et al. (2000) consideram a necessidade diferenciada de cada espécie, recomendando uma faixa de $\mathrm{pH}$ para cada cultura, conforme a sua especificidade de cultivo. Esta faixa, para a maioria dos cultivos de flores ou plantas ornamentais, situa-se entre 5 e 6,5 .

A salinidade pode ser considerada como um dos problemas mais sérios da nutrição de plantas, chegando a limitar o poder nutritivo de um meio de cultivo. A resposta das plantas varia de acordo com diversos fatores, como a cultivar e a espécie, a idade e o desenvolvimento vegetativo, as condições ambientais e as práticas de cultivo (SCHAFER et al., 2008). Ela pode ser mensurada a partir da condutividade elétrica (CE), que indica a concentração de sais ionizados na solução.

Existem diferentes tipos de substratos comerciais para plantas, com formulações distintas. Estes são formulados mediante a mistura de um componente básico e seus complementos (condicionadores). O primeiro entra em maior proporção, chegando a $60 \%$ do volume da mistura e tem a função de dar estrutura ao mesmo. Os condicionadores têm a função de melhorar a retenção de água ou a drenagem, aumentar a porosidade e promover melhor agregação do sistema radicular da planta, podendo chegar a $40 \%$ do volume. E, por fim, os aditivos que têm a função de controlar ou melhorar as características químicas e/ou biológicas do substrato e que entram em menor quantidade (KÄMPF, 2005).

O Laboratório de Substratos para Plantas do Departamento de Horticultura e Silvicultura da Faculdade de Agronomia da UFRGS, inaugurado em 1990, é pioneiro no Brasil em realização de análises físicas e químicas de diversos materiais oriundos de setores de pesquisa ou de produção. O objetivo deste estudo foi apresentar resultados de análises físicas e químicas dos substratos encaminhados ao laboratório nos últimos três anos, visando estabelecer-se um panorama do setor de substratos, comparando-os com valores referenciais citados na literatura.

\section{MATERIAL E MÉTODOS}

Foram compilados resultados de amostras de substratos para plantas (comercializados e utilizados pelo setor privado, além daqueles em teste pela pesquisa) encaminhadas ao Laboratório de Substratos para Plantas do Departamento de Horticultura e Silvicultura da Faculdade de Agronomia da Universidade Federal do Rio Grande do Sul durante os anos de 2012, 2013 e 2014.

Neste período foram realizadas 307 análises físicas e 479 análises químicas, que serviram de base para este estudo. As análises físicas realizadas foram a densidade em base seca e a curva de retenção de água (porosidade total, espaço de aeração, água disponível e água remanescente). A determinação da densidade foi realizada através do Método da Auto-compactação (HOFFMANN, 1970) e as curvas de retenção de água nas tensões de $0 ; 10 ; 50$ e 100 $\mathrm{hPa}$, foram determinadas em funis de tensão, conforme os princípios de De Boodt e Verdonck (1972).

Para as análises químicas foram consideradas as avaliações de condutividade elétrica (CE) e potencial hidrogeniônico $(\mathrm{pH})$, em uma diluição substrato:água de 1:5 (v:v), conforme a IN $\mathrm{n}^{\circ} 17$, de 21 de maio 2007, que estabelece os métodos para análise de substratos para plantas. Todas as análises foram realizadas com três repetições (BRASIL, 2007). Os resultados foram analisados por estatística descritiva e agrupados segundo os valores padrão para cada característica (DE BOODT e VERDONCK, 1972; CAVINS et al., 2000; KÄMPF, 2005).

\section{RESULTADOS E DISCUSSÃO}

Quanto à densidade em base seca, verificou-se que 201 amostras apresentaram entre 100 e $300 \mathrm{~kg} \mathrm{~m}^{-3} ; 177$ apresentaram entre 200 e $500 \mathrm{~kg} \mathrm{~m}^{-3}$, e 30 apresentaram entre $500 \mathrm{a} 800 \mathrm{~kg} \mathrm{~m}^{-3}$ (Figura 1). Segundo Kämpf (2005), valores adequados de densidade em base seca devem ser definidos conforme o tamanho do recipiente, variando de 100 a $300 \mathrm{~kg} \mathrm{~m}^{-3}$ para bandejas multicelulares, de 200 a $400 \mathrm{~kg} \mathrm{~m}^{-3}$ para vasos de até $15 \mathrm{~cm}$ de altura, de 300 a $500 \mathrm{~kg} \mathrm{~m}^{-3}$ para vasos de 20 a $30 \mathrm{~cm}$ de altura e de 500 a $800 \mathrm{~kg} \mathrm{~m}^{-3}$ para vasos maiores de $30 \mathrm{~cm}$ de altura. Nos resultados ressalta-se que densidades de 200 a $300 \mathrm{~kg} \mathrm{~m}^{-3}$; podem ser usadas tanto para bandejas quanto para vasos até $15 \mathrm{~cm}$, sendo estes substratos inseridos em ambos os grupos. A grande maioria, das 307 amostras analisadas $(89,25 \%)$, está dentro das faixas recomendadas. Entretanto, apesar do número reduzido de casos, merecem destaque alguns valores extremos, como $1713 \mathrm{~kg} \mathrm{~m}^{-3}$ (elevado) ou $15,5 \mathrm{~kg} \mathrm{~m}^{-3}$ (baixo), sendo o primeiro uma areia e o segundo aparas de corte de gramados. Estes materiais podem ser usados como complementos em uma mistura para formar um substrato, mas não como produtos únicos. 


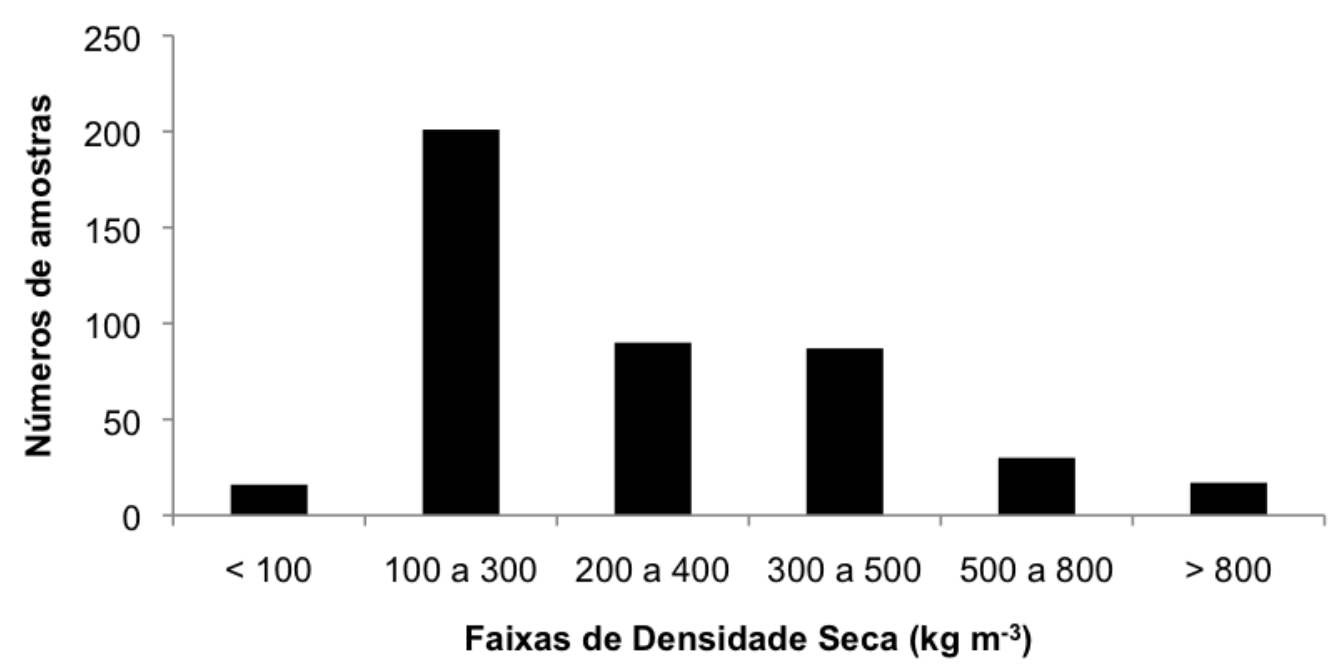

Figura 1. Número de amostras por faixa de densidade em base seca $\left(\mathrm{kg} \mathrm{m}^{-3}\right)$, conforme recomendação de uso de Kämpf (2005), determinadas em laboratório comercial (Laboratório de Substratos para Plantas do Departamento de Horticultura e Silvicultura da Faculdade de Agronomia da Universidade Federal do Rio Grande do Sul).

Figure 1. Number of samples per range bulk density (dried) ( $\left.\mathrm{kg} \mathrm{m}^{-3}\right)$, as recommended usage by Kämpf (2005), determined in a commercial laboratory (Laboratório de Substratos para Plantas - Departamento de Horticultura e Silvicultura - Faculdade de Agronomia - Universidade Federal do Rio Grande do Sul).

Um substrato de referência tem como constituinte, em suas características físicas, uma parte de sólidos (15\%) e o restante de poros, apresentando uma relação poros:sólidos equilibrada a fim de permitir trocas gasosas eficientes (KÄMPF, 2005). Observa-se que 180 amostras (58,5\% do total) apresentaram valores próximos da faixa referencial de porosidade total (Figura 2A), que é de 85\% (80-90\%), segundo De Boodt e Verdonck (1972) e Kämpf (2005).

Observa-se que somente $31 \%$ das amostras analisadas (106) apresentam espaço de aeração dentro da faixa considerada ideal por De Boot e Verdonck (1972), que é de 20-30\% (Figura 2B). Ainda, 43,85\% das amostras (150) apresentam valores acima do ideal, indicando substratos com alta capacidade de drenagem, enquanto que o restante $(25,15 \%)$ apresenta valores abaixo do ideal, potencialmente com elevada retenção de água. Essas diferenças repercutem diretamente no manejo de irrigação em condições de cultivo, pois as características do material em relação à sua capacidade de retenção de água determinarão a necessidade da irrigação. Em função disso, muitos substratos, com excelentes propriedades físicas, podem ser caracterizados como ineficientes, porque o manejo da irrigação não está de acordo com as suas características.

Valores de 25 a $35 \%$ para a água disponível são relatados como ideais na bibliografia (DE BOODT e VERDONCK, 1972; CATTIVELLO, 1991; SCHAFER et al., 2008). Observa-se que somente $22,1 \%$ das amostras analisadas encontram-se dentro desta faixa, sendo que a grande maioria $(75,3 \%)$ apresenta valores inferiores (Figura 2C). Com valores reduzidos de água disponível o manejo da irrigação deve ser eficiente para não haver desperdício de água, neste caso recomenda-se aumentar o número de irrigações e diminuir o volume aplicado ou usar um condicionador para aumentar estes valores.

Substratos com volumes altos de água remanescente (>30\%) apresentam drenagem insatisfatória (KÄMPF, 2005). Somente $36,8 \%$ das amostras estão dentro da faixa considerada ideal, observando-se que a maioria (48,5\%) está acima desta, indicando alta retenção de água indisponível à planta (Figura 2D). Neste tipo de material, recomenda-se a mistura com condicionadores que apresentem baixos percentuais de água remanescente, pois, do contrário, a dificuldade de drenagem acarretará insuficiente disponibilidade de oxigênio às raízes.

A análise descritiva dos dados apontou valores médios de $\mathrm{pH}$ de 6,2, com mínimo de 3,51 e máximo de 9,32, e com um desvio padrão de 1,34. Para os resultados referentes às faixas de $\mathrm{pH}$, observa-se que a maioria dos substratos $(43,9 \%)$ se encontram dentro da faixa recomendada $(5-6,5)$ para plantas ornamentais, segundo Cavins et al. (2000) (Figura 3A). No entanto, para Kämpf (2005) somente 15\% das amostras são consideradas com pH ótimo $(5,2-5,5)$ (Figura 3 B). 


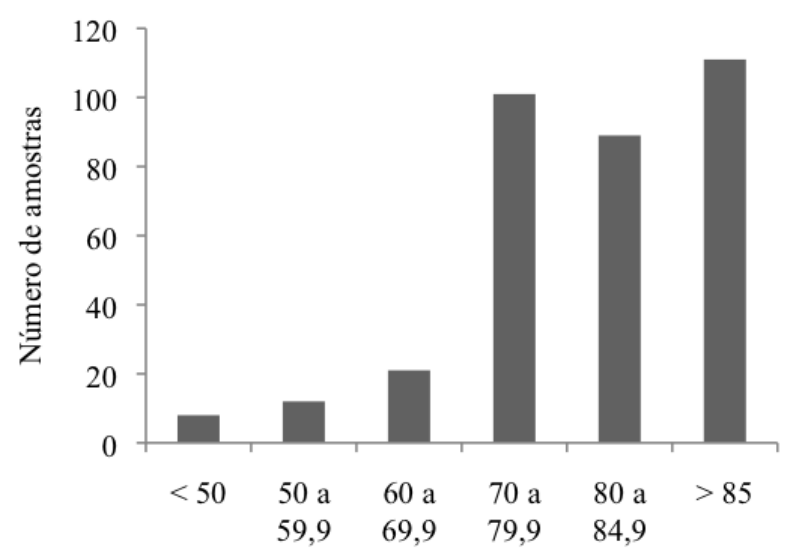

A

Faixa de Porosidade Total (\%)

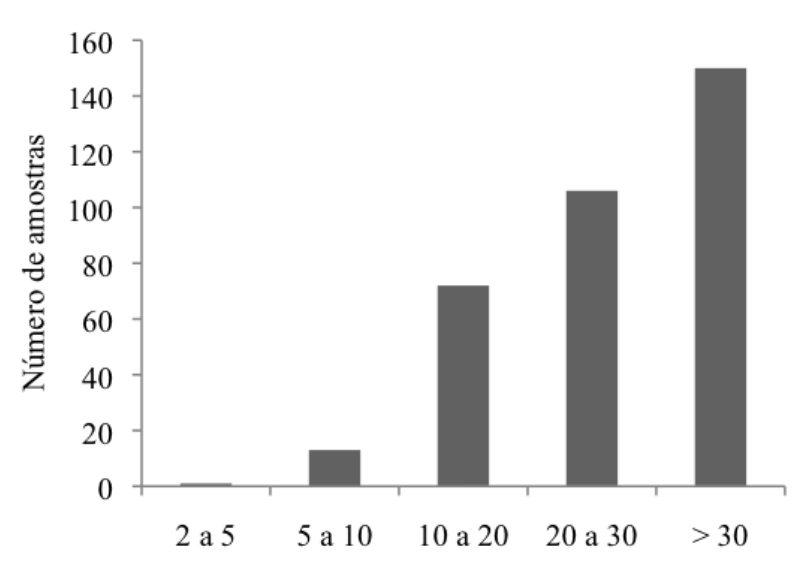

B
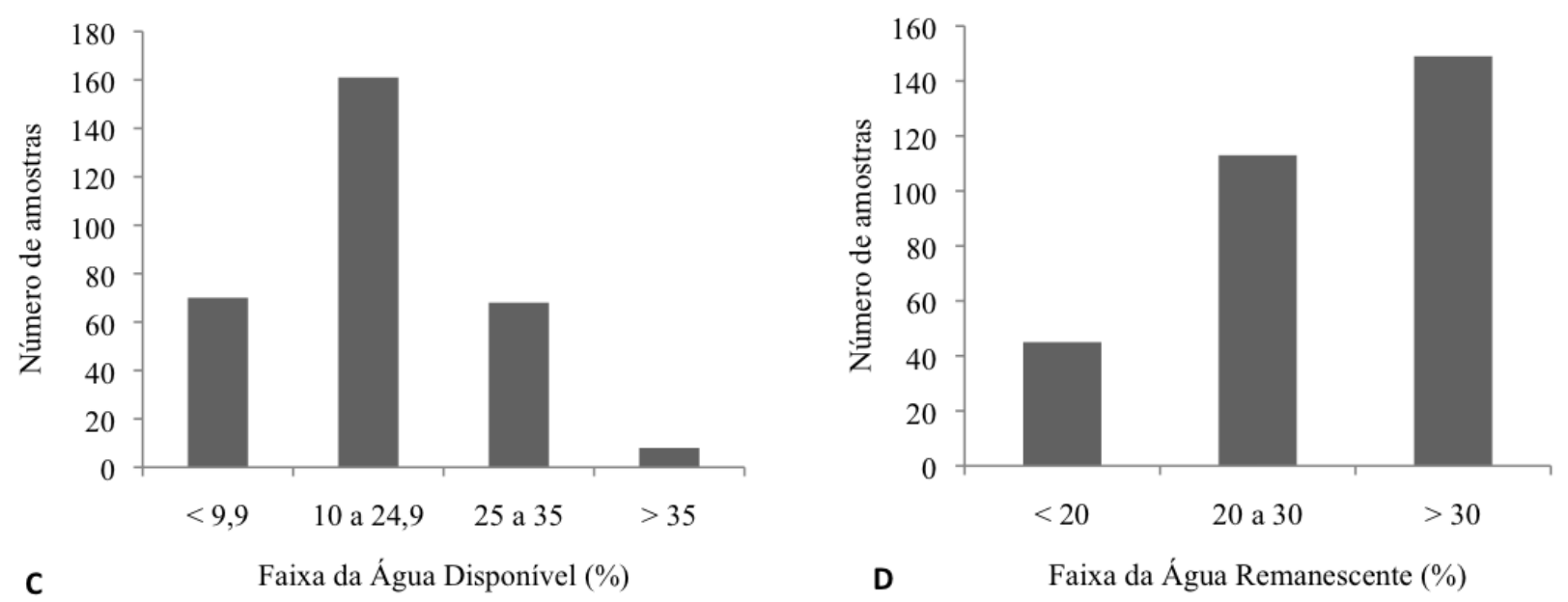

Figura 2. Percentual de amostras por faixa de porosidade total (A), espaço de aeração (B), água disponível (C) e água remanescente (D), determinadas em laboratório comercial (Laboratório de Substratos para Plantas do Departamento de Horticultura e Silvicultura da Faculdade de Agronomia da Universidade Federal do Rio Grande do Sul).

Figure 2. Percent of samples ranged per total porosity (A), air space (B), available water (C) and remaining water (D), determined in a commercial laboratory (Laboratório de Substratos para Plantas - Departamento de Horticultura e Silvicultura - Faculdade de Agronomia - Universidade Federal do Rio Grande do Sul).

Apenas uma pequena parcela (10,4 e 18,6\% - Figuras $3 \mathrm{~A}$ e $3 \mathrm{~B}$, respectivamente) de amostras apresentou $\mathrm{pH}$ que pode ser considerado baixo (ácido). Normalmente estas amostras são à base de turfas, naturalmente mais ácidas (KÄMPF, 2005). A correção do pH de substratos com essa condição é de relativa facilidade, visto que pode-se utilizar carbonato de cálcio (calcário agrícola), produto com custo baixo e de fácil aquisição pela disponibilidade no mercado (KÄMPF, 2005).

Por outro lado, cabe destacar a grande quantidade de amostras com $\mathrm{pH}$ elevado. Somando-se todas as amostras com valor de $\mathrm{pH}>6,5,45,7 \%$ destas estão com valores acima da faixa aceitável, de acordo com parâmetros citados por Cavins et al. (2000) (Figura 3A). No entanto, utilizando os referenciais apontados por Kämpf (2005) (Figura 3 B), 9,8\% das amostras podem ser consideradas com $\mathrm{pH}$ levemente alto $(5,6-5,8), 31,3 \%$ alto $(5,9-6,3)$ ou muito alto $(6,4-6,8)$ e $25,3 \%$ com valores extremamente altos $(>6,9)$, o que corresponde no total de $66,4 \%$ das amostras analisadas. O manejo do $\mathrm{pH}$ elevado é mais difícil e oneroso, visto que emprega a utilização de adubos de base ácida ou a aplicação de acidificantes, como por exemplo enxofre elementar. Boaro et al. (2014), trabalhando com substrato alcalino ( $\mathrm{pH}$ original próximo de 8), utilizou doses de até $16 \mathrm{~g} \mathrm{~L}^{-1}$ de enxofre elementar, conseguindo diminuir para índices aceitáveis, entretanto aumentando em demasia a condutividade elétrica (CE). Contudo, a proporção de enxofre a ser utilizado parece estar diretamente relacionada à composição do substrato, pois Kämpf et al. (2009) alcançou resultados satisfatórios reduzindo o $\mathrm{pH}$ de fibra de coco + argila expandida (1:2, volume) com apenas $0,5 \mathrm{~g}$ de enxofre por litro de substrato, sem prejuízos sobre a elevação a condutividade elétrica. Diante disso, cabe ressaltar a necessidade de maiores estudos visando a identificação de protocolos para a correção de $\mathrm{pH}$ de substratos alcalinos, de forma 

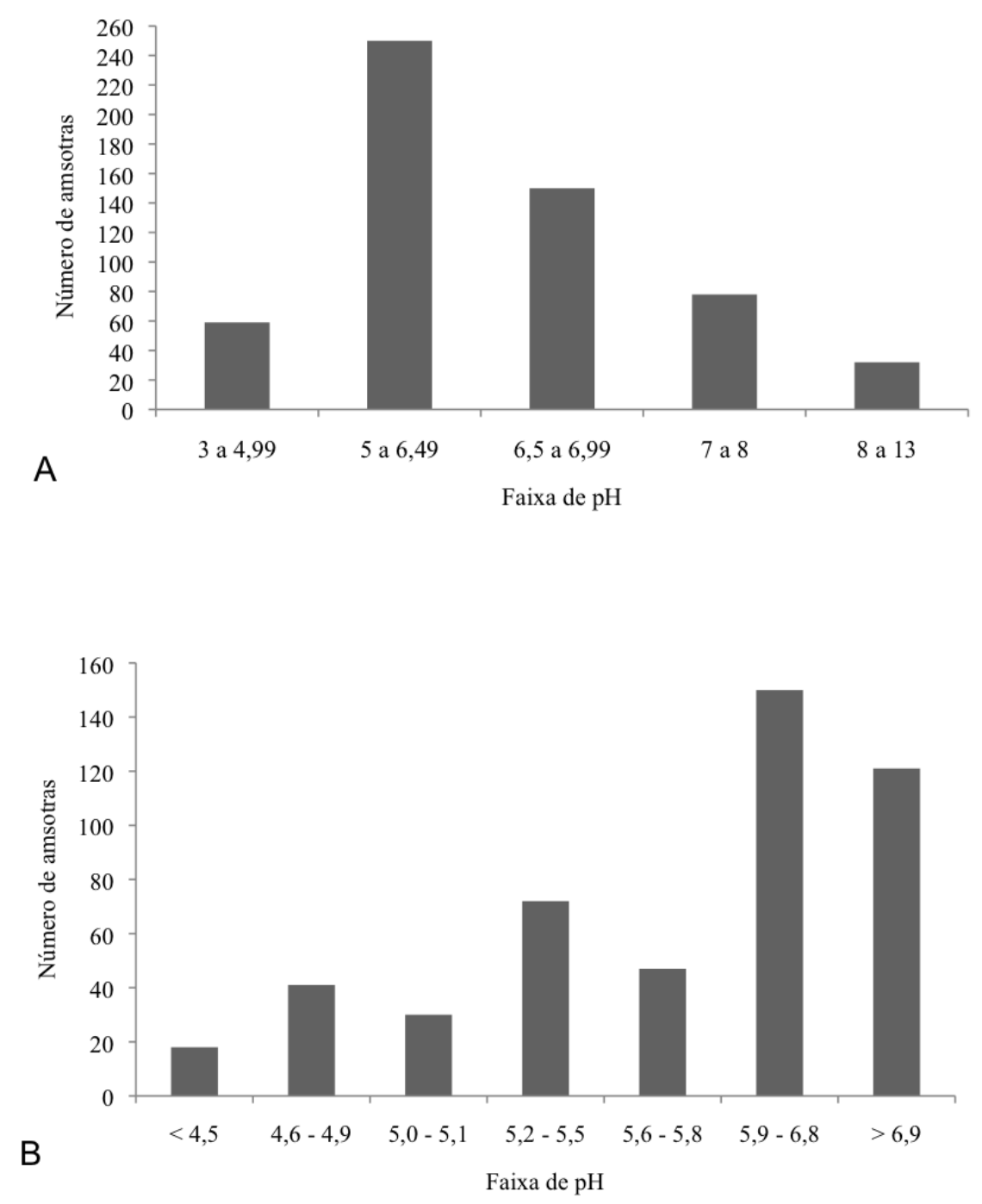

Figura 3. Percentual de amostras por faixa de $\mathrm{pH}$ em água (1:5-v:v), segundo valores considerados por Cavins et al. (2000) (A) e Kämpf, (2005) (B), determinadas em laboratório comercial (Laboratório de Substratos para Plantas do Departamento de Horticultura e Silvicultura da Faculdade de Agronomia da Universidade Federal do Rio Grande do Sul).

Figure 3. Percentage of samples ranged per $p H$ in water (1:5, v:v) according to Cavins et al. (2000) (A) and Kämpf, (2005) (B), determined in a commercial laboratory (Laboratório de Substratos para Plantas - Departamento de Horticultura e Silvicultura - Faculdade de Agronomia - Universidade Federal do Rio Grande do Sul).

a mantê-los em índices aceitáveis, tanto de $\mathrm{pH}$ como de condutividade elétrica.

Substratos com CE entre 0,36 e $0,65 \mathrm{mS} \mathrm{cm}^{-1}(1: 5-$ $\mathrm{v}: \mathrm{v})$ podem ser considerados normais (CAVINS et al., 2000). Os autores classificam as plantas ornamentais como de baixa, média e alta exigência em adubação, sendo considerado que aquelas altamente exigentes toleram $\mathrm{CE}$ de até $0,65 \mathrm{mS} \mathrm{cm}^{-1}$ (no método 1:5). Observou-se que $56,4 \%$ das amostras analisadas estão na faixa de até
$0,65 \mathrm{mS} \mathrm{cm}^{-1}$ (Figura 4), entretanto, também nota-se que uma quantidade muito grande $(43,6 \%)$ de amostras com valores acima do considerado normal. Neste caso, estes materiais podem ser usados, mas com restrição. Devem ser evitados, principalmente nas etapas de estabelecimento de plantas (semeadura, enraizamento e no estabelecimento de culturas). Em casos extremos, onde não haja possibilidade de substituição do substrato, sugere-se fazer uma lixiviação dos sais. 


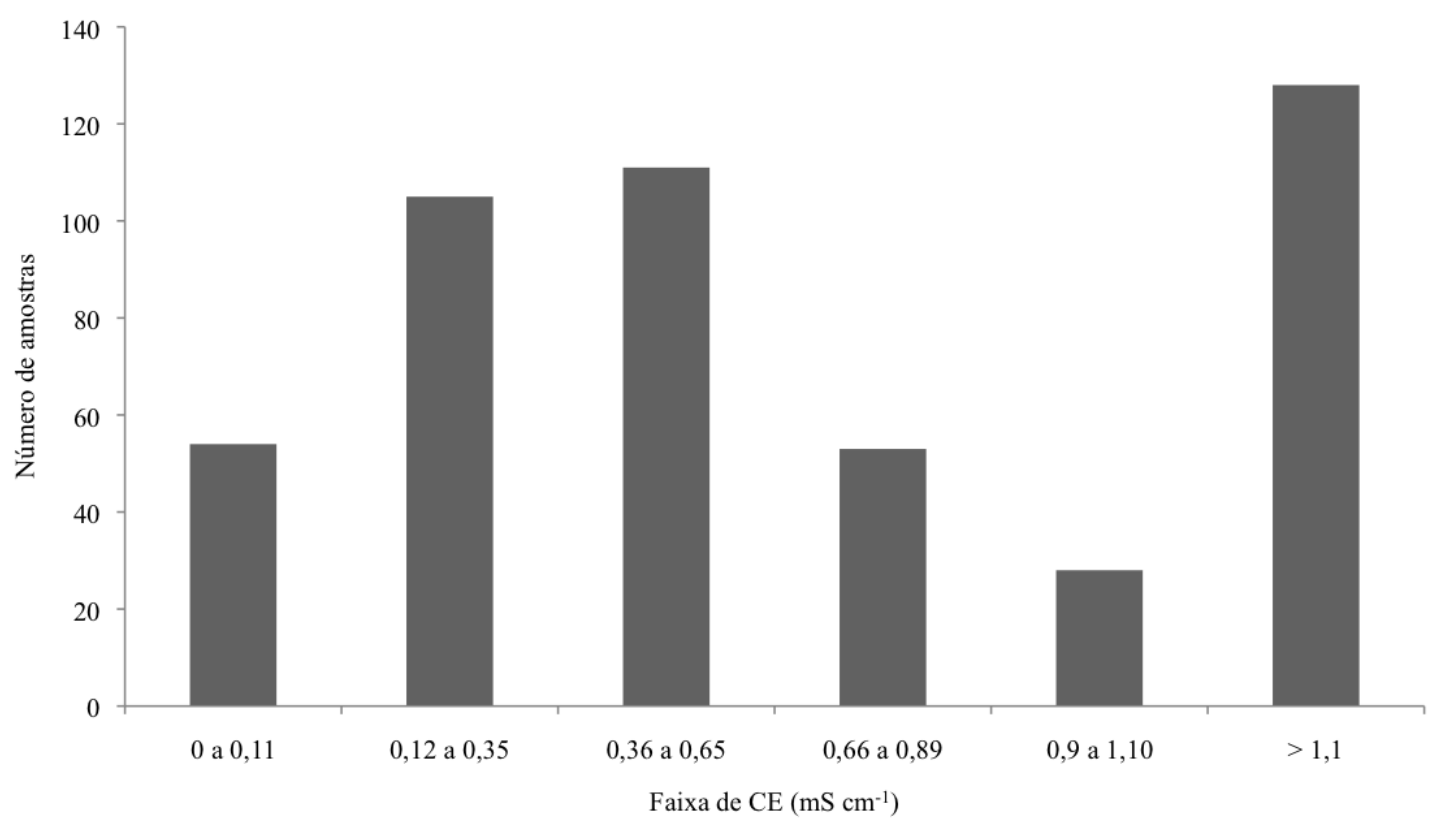

Figura 4. Percentual de amostras, por faixa de condutividade elétrica $\left(\mathrm{mS} \mathrm{cm}^{-1}\right)$, segundo Cavins et al. (2000), determinadas em laboratório comercial (Laboratório de Substratos para Plantas do Departamento de Horticultura e Silvicultura da Faculdade de Agronomia da Universidade Federal do Rio Grande do Sul).

Figure 4. Percentage of samples ranged per electric conductivity $\left(\mathrm{mS} \mathrm{cm}^{-1}\right)$ according to Cavins et al. (2000), determined in a commercial laboratory (Laboratório de Substratos para Plantas - Departamento de Horticultura e Silvicultura - Faculdade de Agronomia - Universidade Federal do Rio Grande do Sul).

Os componentes constituintes dos substratos não foram discriminados na maioria das amostras encaminhadas ao laboratório, tanto por uma privacidade das empresas, como por inexigibilidade legal. Contudo, por análise visual levando em consideração a experiência dos autores, os materiais básicos encontrados com maior frequência foram turfa, cascas de árvores (pinus, eucalipto e acácia negra), solo mineral, areia, cama de aviário, casca de coco e casca de arroz carbonizada. Já os complementos mais observados foram a vermiculita, a casca de arroz carbonizada ou queimada, cinzas e estercos de animais decompostos. Estes materiais são de fácil visualização no substrato por apresentarem características (cor, forma, etc.) conhecidas.

Há uma diversidade muito grande em tipos e proporções de componentes utilizados como substratos para plantas no sul do Brasil. A utilização de componentes minerais ainda é observada em muitos casos, o que, normalmente, acarreta em substratos com características de cultivo muito deficientes. Nesse sentido, percebeuse ainda um grande desconhecimento técnico na área quando se observou a formulação de substratos através da mistura de materiais orgânicos, de boas qualidades físicas, com grandes proporções de solo mineral, o que não se justifica, uma vez, sem exceções, a qualidade da mistura ser inferiores ao material orgânico original. Além disso, a utilização de solo em grandes proporções em viveiros leva à insustentabilidade, uma vez que a sua extração provoca degradação ambiental em diferentes proporções.
Outro fator a ser considerado é a falta de critérios na utilização de materiais como esterco de animais na composição de material básico para substratos, mesmo como matriz orgânica, pois devido à alta concentração de sais, esses componentes deveriam entrar nas formulações somente como aditivos, ou seja, em pequenas proporções. Kämpf (2005) descreve alguns materiais usados como substratos hortícolas e cita problema de excesso de sais em alguns compostos orgânicos. Neste trabalho percebeu-se que alguns dos maiores valores de CE foram obtidos em substratos que continham cama de aviário, estercos em geral ou compostos domésticos.

\section{CONCLUSÕES}

Em virtude da diversidade de constituintes empregados para formação de substratos no sul do Brasil, grande parte das amostras analisadas tem problemas em suas características físicas, destoando das faixas ideais de espaço de aeração, água disponível e água remanescente. Além disso, os substratos utilizados em cultivo no sul do Brasil são, em sua maioria, alcalinos e apresentam excesso de sais em sua constituição.

\section{AGRADECIMENTOS}

Os autores agradecem a FAPERGS e ao CNPq pelo auxílio financeiro. 


\section{REFERÊNCIAS}

BOARO, V.; SCHWARZ, S.F.; SOUZA, P.V.D.; SOARES, W.L., G.V. Enxofre elementar no manejo do $\mathrm{pH}$ de substrato orgânico alcalino. Ciência Rural, Santa Maria, v.44, n.12, p.1610-1614, 2014. DOI: http://dx.doi.org/10.1590/0103$8478 \mathrm{cr} 2013076$.

BRASIL. Ministério da Agricultura, Pecuária e abastecimento (MAPA). Secretaria de Defesa Agropecuária (SDA). Instrução Normativa SDA N $N^{o} 17$ de 21 de maio de 2007. Métodos Analíticos Oficiais para Análise de Substratos e Condicionadores de Solos. Diário Oficial da União, Brasília, DF, 24 de maio 2007. Disponível em: $\quad<$ http://extranet.agricultura.gov.br/sislegis-consulta/ servlet/VisualizarAnexo?id=14783>. Acesso em: 21 maio de 2015.

BUNT, A.C. Some physical and chemical characteristics of loamless pot-plant substrates and their relation to plant growth. Plant and Soil, Dordrecht, n.38, p.1957-1965, 1973.

CATTIVEllo, C. Physical properties in commercial substrates and their relationships. Acta Horticulturae, Wageningen, v.294, p.207-214, 1991.

CAVINS, T.J.; WHIPKER, B.E.; FONTENO, W.C.; HARDEN, B.; MCCALL, I.; GIBSON, J.L. Monitoring and managing $\mathrm{pH}$ and $\mathrm{EC}$ using the PourThru Extraction Method. Horticulture Information Leaflet 590, New 7/2000. Raleigh: North Caroline State University, 2000. 17p.
CONOVER, C.A. Soil amendments for pot and field grown flowers. Florida Flower Grower, Florida, v.4, n.4, p.1-4, 1967.

DE BOODT, M.; VERDONCK, O. The physical properties of the substrates in horticulture. Acta Horticulturae, Wageningen, v.26, p.37-44, 1972.

HOFMANN, G. Verbindliche methoden zur untersuchung von TKS und gartnerischen erden. Mitteilungen der VSLUFA, Heft, v.6, p.129-153, 1970.

KÄMPF, A.N. Produção comercial de plantas ornamentais. Guaíba: Agropecuária, 2005. 256p.

KÄMPF, A.N.; FIOR, C.S.; LEONHARDT, C. Lowering $\mathrm{pH}$ value with elemental sulfur in the substrate for ex vitro acclimatization. Acta Horticulturae, Leuven v.812, p.415-420, 2009.

SCHAFER, G.; SOUZA, P.V.D.; KOLLER, O.C.; SCHWARZ, S.F. Physical and chemical properties of substrates to cultivate seedling of citrus rootstocks. Communications in Soil Science and Plant Analysis, New York, v.39, p.1067-1079, 2008. DOI: http://dx.doi. org/10.1080/00103620801925547.

SCHMITZ, J.A.K.; SOUZA, P.V.D.; KAMPF, A.N. Propriedades químicas e físicas de substratos de origem mineral e orgânica para o cultivo de mudas em recipientes. Ciência Rural, Santa Maria, v.32, n.6, p.937-944. DOI: http://dx.doi.org/10.1590/S0103-84782002000600005. 
